\title{
Estado nutricional relativo ao zinco de crianças que frequentam creches do estado da Paraíba
}

\author{
Zinc nutritional status in children attending \\ public daycare centers in the state \\ of Paraíba, Brazil
}

Dixis FIGUEROA PEDRAZA ${ }^{1}$

Ana Carolina Dantas ROCHA ${ }^{1}$

Everton Oliveira de QUEIROZ²

Carolina Pereira da Cunha SOUSA ${ }^{1}$

\section{RE S U M O}

\section{Objetivo}

Avaliar o estado nutricional relativo ao zinco de crianças assistidas em creches do Estado da Paraíba.

\section{Métodos}

O estado nutricional relativo ao zinco de 235 crianças pré-escolares foi avaliado através de sua concentração no soro, da ingestão dietética de zinco e da estatura para idade, como recomendado pelo International Zinc Consultative Group. As concentrações séricas de zinco foram determinadas por espectrofotometria de absorção atômica de chama, considerando deficiência de zinco valores $<65 \mu \mathrm{mol} / \mathrm{L}$. O consumo alimentar foi registrado mediante o recordatório de 24 horas, considerando a alimentação da criança no dia anterior e o consumo de alimentos na creche, e foi analisada a inadequação dietética de zinco de acordo com as necessidades médias estimadas de zinco segundo etapa da vida e tipo de dieta estabelecido pelo International Zinc Consultative Group. Adotou-se o Padrão de Crescimento Infantil da Organização Mundial da Saúde para o índice estatura para idade, considerando-se com deficit de estatura as crianças que apresentaram esse índice dois escores-Z abaixo do valor mediano da população de referência. Empregou-se o teste $t$ ou análise de variância na análise estatística, programa Statistical Package for the Social Sciences-16.0.

\section{Resultados}

As prevalências de deficiência de zinco no soro, inadequação dietética de zinco e deficit de estatura foram de $16,2 \%, 16,6 \%$ e $7,7 \%$, respectivamente. A média de zinco no soro foi estatisticamente menor nas crianças de mães com baixo peso em comparação com as crianças de mães com peso normal.

\footnotetext{
1 Universidade Estadual da Paraíba, Núcleo de Estudos e Pesquisas Epidemiológicas. Av. das Baraúnas, 351, Universitário, 58429-500, Campina Grande, PB, Brasil. Correspondência para/Correspondence to: D. FIGUEROA PEDRAZA. E-mail: <dixisfigueroa@gmail.com>.

2 Universidade Federal da Paraíba, Laboratório de Tecnologia Farmacêutica. João Pessoa, PB, Brasil.
} 


\section{Conclusão}

As crianças estudadas apresentaram risco moderado de deficiência de zinco, pois são indicadas prevalências significativas de baixos níveis séricos de zinco, de consumo inadequado de zinco e de desnutrição crônica.

Termos de indexação: Creches. Estado nutricional. Pré-escolar. Zinco.

\section{A B S T R A C T}

\section{Objective}

This study assessed the zinc levels of children attending public daycare centers in the state of Paraíba. Brazil.

\section{Methods}

The zinc levels of 235 preschool children were evaluated through serum zinc concentration, dietary zinc intake and height-for-age, as recommended by the International Zinc Nutrition Consultative Group. Baseline zinc levels in the serum were measured by flame atomic absorption spectrophotometry, considering values $<65 \mu$ moll $L$ indicative of zinc deficiency. The 24-hour recall method was used to record food consumption, considering the food consumption of the child the day before and in the daycare center. Zinc inadequacy was analyzed according to the estimated average zinc requirement by life stage and diet type recommended by the International Zinc Nutrition Consultative Group. The World Health Organization Growth Reference was used as the reference for the height-for-age indices. Children with indices two z-scores below the median value of the reference population were considered stunted. Statistical analysis was performed by the t-test or analysis of variance by the software Statistical Package for the Social Sciences -16.0.

\section{Results}

The prevalence of inadequate serum zinc concentration, inadequate zinc intakes and stunting were $16.2 \%$, $16.6 \%$ and $7.7 \%$, respectively. Mean serum zinc was lower in children of underweight mothers than in children of normal weight mothers.

\section{Conclusion}

The studied children presented moderate risk of zinc deficiency because there was a significant prevalence of low serum zinc concentrations, inadequate zinc intakes and stunting. Also, some children were chronically malnourished.

Indexing terms: Child day care centers. Nutritional status. Child, preschool. Zinc.

\section{N T R O D U Ç Ã O}

Em geral, a deficiência de micronutrientes é considerada um dos fatores de risco mais determinantes do problema de deficit de crescimento em crianças, sendo, pelo seu impacto, o zinco, a vitamina A e o ferro os de maior importância nesse caso. As deficiências de ferro e vitamina A afetam o crescimento somente em condições de deficiência severa (retinol sérico $<0,35 \mu \mathrm{mol} / \mathrm{L}$, $\mathrm{Hb}<9,5 \mathrm{~g} / \mathrm{dL}$ ). Caso diferente é observado na deficiência de zinco (zinco sérico $<65 \mu \mathrm{g} / \mathrm{dL}$ ), considerada a de maior importância no crescimento e, portanto, a causa mais comum desse deficit, tanto nas áreas onde a prevalência do problema é alta como naquelas de deficiência leve ou moderada, onde também o zinco tem um papel muito importante'.

Pouca informação está disponível sobre a prevalência da deficiência de zinco, embora tenha sido estimado que cerca de metade da população mundial está em risco de ingestão insuficiente de zinco alimentar absorvível. Apesar de a deficiência de zinco ocorrer sobretudo em países subdesenvolvidos e em bolsões de pobreza de grandes cidades, estima-se que ela afete cerca de um terço da população do mundo, com estimativas variando de 4 a $73 \%^{1,2}$.

Dados nacionais a respeito da prevalência da deficiência de zinco, baseados em medidas diretas de estado nutricional, são inexistentes na maioria dos países. O México é um dos poucos 
países que tem incluído avaliação dietética da adequação da ingestão de zinco e avaliação bioquímica em escala nacional. Os resultados, baseados na concentração de zinco sérico, indicam que aproximadamente $25 \%$ das crianças menores de 12 anos de idade têm alguma evidência de deficiência de zinco ${ }^{3}$.

Não há um indicador suficientemente sensível e especifico para diagnosticar a deficiência de zinco, o que torna sua avaliação complexa ${ }^{4}$. Estimativas sobre a deficiência de zinco no Brasil podem ser realizadas considerando a prevalência de desnutrição crônica em crianças menores de cinco anos, o risco de inadequação do consumo de zinco alimentar e a prevalência de anemia por deficiência de ferro. Atendendo a esses fatores, pode-se considerar o Brasil como um país com risco moderado de deficiência de zinco ${ }^{5}$.

Existem poucos trabalhos na literatura científica latino-americana que abordem a associação entre deficiência de micronutrientes, principalmente de zinco, e o deficit de estatura infantil. O desenvolvimento de pesquisas que possibilitem um melhor entendimento sobre tal associação, principalmente quando identificadas prevalências significativas de deficit de estatura, é de grande importância para a saúde pública. Dados de 2006 indicam que $7 \%$ das crianças brasileiras apresentam essa deficiência ${ }^{6}$, o que denota relevância do ponto de vista de saúde pública. Assim, estabelece-se a necessidade de pesquisas nesse contexto, sendo imprescindíveis estudos de âmbito nacional e em populações ou grupos de risco.

É reconhecido que a deficiência de zinco está associada a condições sociais e econômicas adversas, tais como a pobreza, pouca disponibilidade de alimentos de qualidade, falta de educação nutricional e condições de saneamento inadequadas. Assim, a identificação de grupos de risco, independente da região do país, deve estar baseada em variáveis socioeconômicas e demográficas $^{5}$.

Considerando que o seguimento contínuo ou periódico do estado nutricional da população constitui uma ferramenta útil e das mais importantes para a descrição da epidemiologia do deficit de estatura e da deficiência de micronutrientes, o presente estudo teve como objetivo avaliar o estado nutricional relativo ao zinco de crianças assistidas em creches do Estado da Paraíba, com a utilização de um conjunto de indicadores, e examinar variáveis explicativas das concentrações de zinco no soro. Espera-se que as informações geradas sejam de extrema importância para a identificação dos segmentos da população de maior vulnerabilidade à deficiência de zinco, assim como para um melhor entendimento dos fatores de risco que ajude na seleção de estratégias de intervenção apropriadas.

\section{MÉ T O D O S}

Realizou-se estudo transversal, integrado a um projeto mais amplo intitulado "Crescimento, desenvolvimento cognitivo e deficiências de micronutrientes: Perfil das crianças assistidas no Núcleo de Creches do Governo da Paraíba". O estudo foi desenvolvido em creches da Secretaria de Estado do Desenvolvimento Humano do Governo da Paraíba. Ao todo funcionam 45 creches em bairros distintos das cidades beneficiadas, situadas, geralmente, em áreas carentes que abrigam crianças de famílias de baixa renda (com renda familiar entre um e dois salários mínimos). O benefício está presente em oito municípios paraibanos: João Pessoa (30 creches), Campina Grande (9 creches), além das cidades de Areia, Bayeux, Mamanguape, Itaporanga, Soledade e Umbuzeiro (cada uma delas com uma creche). O universo é de 3310 crianças beneficiadas: 2317 no município de João Pessoa, 621 no município de Campina Grande e 372 nos outros municípios.

Foi selecionada uma amostra probabilística de creches da Secretaria de Estado do Desenvolvimento Humano do Governo da Paraíba, utilizando-se um procedimento de amostragem por conglomerados em duas etapas. Para garantir a representatividade dos municípios, o sistema de referência para a primeira etapa de amostragem 
foi ordenado segundo estratos (João Pessoa, Campina Grande, outros municípios), possibilitando a obtenção de um tamanho amostral apropriado para cada estrato. Considerou-se também o porte da creche, isto é, o número de crianças por creche. $\mathrm{Na}$ segunda etapa de amostragem, foram sorteadas, nas 14 creches selecionadas de forma aleatória na primeira etapa, as crianças a serem avaliadas. A opção para determinar o tamanho da amostra do estudo foi o procedimento de amostragem para proporções:

$$
\begin{aligned}
& \mathrm{n}=\frac{\mathrm{N} * \mathrm{Z}_{\alpha}{ }^{2 *} p^{*} q}{\mathrm{~d}^{2 *}(\mathrm{~N}-1)+\mathrm{Z}_{\alpha}{ }^{*} p^{*} q} \\
& \mathrm{n}=\frac{\mathrm{N} * \mathrm{Z}_{\alpha}{ }^{2 *} p^{*} q}{\mathrm{~d}^{2 *}(\mathrm{~N}-1)+\mathrm{Z}_{\alpha}{ }^{*} p^{*} q}
\end{aligned}
$$

onde N é o total da população; $Z \alpha^{2}=1,96^{2}$ (se a confiança é do $95 \%$ ); $p$ é a proporção esperada; $q=1-p, d$ é a precisão arbitrária (erro de estimação). Considerou-se $\mathrm{p}=7,0 \%$ (média do deficit de estatura para o Brasil) e $d=3 \%$, totalizando 256 crianças entre 6 e 72 meses que foram sorteadas de forma aleatória no momento do trabalho de campo.

O desenvolvimento do trabalho incluiu o preenchimento de um questionário pelas mães ou responsáveis pelas crianças, por meio de entrevista individualizada, contendo informações sobre aspectos relacionados com a situação de saúde da criança; a avaliação do consumo de alimentos das crianças; a avaliação antropométrica das crianças e de suas mães; e a avaliação bioquímica do estado nutricional de micronutrientes das crianças. A ficha de identificação e o cartão de saúde das crianças, documentos obrigatórios nas creches, foram utilizados como fonte de informação de algumas características das crianças e das condições socioeconômicas das famílias. Treinamento e padronização, seguindo técnicas internacionais, foram realizados nos casos necessários ${ }^{7}$.

A avaliação do consumo de alimentos foi realizada por recordatório de 24 horas, considerando a alimentação no dia anterior e o consumo de alimentos na creche. Foi utilizado o álbum de registros fotográficos com o fim de diminuir erros e obter resultados mais confiáveis ${ }^{8}$. Considerando a importância da biodisponibilidade de zinco na sua absorção pelo organismo, a alimentação das crianças foi classificada, segundo sua biodisponibilidade, em: (i) dieta de baixa biodisponibilidade de zinco, quando baseada em cereais não refinados e/ou legumes, ou (ii) dieta de adequada biodisponibilidade de zinco, quando mista ou baseada em cereais refinados. Em seguida, foi determinada a adequação dietética de zinco, comparando a quantidade de zinco alimentar ingerido com as necessidades médias estimadas de zinco segundo idade, sexo, estado fisiológico e tipo de dieta, segundo recomendações do International Zinc Nutrition Consultative Group (IZiNCG) $)^{5}$. (Quadro 1). Os cálculos para quantificar o zinco dietético foram realizados com o auxílio do software Virtual Nutri.

Para a avaliação antropométrica, as medidas de comprimento (crianças menores de 24 meses) e a estatura (crianças de 25 - 72 meses), assim como o peso e a estatura da mãe, foram obtidas utilizando equipamentos e técnicas padronizadas, obedecendo aos procedimentos recomendados pela Organização Mundial da Saúde $(\mathrm{OMS})^{9}$. Para avaliação do estado nutricional das crianças, foram considerados os índices comprimento/idade e estatura/idade, comparados com os padrões de crescimento infantil da OMS ${ }^{10}$, utilizando o programa WHO Anthro 2005 versão beta. Foram consideradas com deficit nutricional todas as crianças que apresentaram índices dois escores-Z abaixo do valor mediano da população de referência ( $<-2$ escores-Z como ponto de corte para classificar deficit nutricional). A baixa estatura materna foi definida pelo ponto de corte $155 \mathrm{~cm}$. Esse valor corresponde ao percentil 5 da relação estatura para idade, sendo a idade igual a 20 anos, já que, depois disso, perde-se a capacidade de crescer. Segundo a OMS, a adolescência corresponde à faixa entre 10 e 19 anos) ${ }^{11,12}$. Para o caso do Índice de Massa Corporal (IMC), foram utilizados os pontos de corte indicados pela OMS. 
Quadro 1. Necessidades médias estimadas de zinco (mg/dia) segundo etapa da vida e tipo de dieta estabelecido pelo IZiNCG.

\begin{tabular}{|c|c|c|c|c|}
\hline \multicolumn{5}{|c|}{ Zinco (mg/dia) } \\
\hline \multicolumn{3}{|r|}{ Condições } & \multicolumn{2}{|c|}{ Valores de referência } \\
\hline Idade & Sexo & Peso corporal de referência $(\mathrm{kg})$ & Dieta de adequada biodisponibilidade & Dieta de baixa biodisponibilidade \\
\hline 6-11 meses & $M+F$ & 9 & $3 \mathrm{mg} / \mathrm{dia}$ & $4 \mathrm{mg} / \mathrm{dia}$ \\
\hline $1-3$ anos & $\mathrm{M}+\mathrm{F}$ & 12 & $2 \mathrm{mg} / \mathrm{dia}$ & $2 \mathrm{mg} / \mathrm{dia}$ \\
\hline 4-8 anos & $\mathrm{M}+\mathrm{F}$ & 21 & $3 \mathrm{mg} / \mathrm{dia}$ & $4 \mathrm{mg} / \mathrm{dia}$ \\
\hline
\end{tabular}

IZiNCG: International Zinc Nutrition Consultative Group; M: masculino; F: feminino.

Para a avaliação bioquímica, foram coletados ${ }^{(3)}$, por técnicos com experiência na coleta de sangue em crianças, $5 \mathrm{~mL}$ de sangue por punção venosa periférica. As amostras de sangue foram colhidas em tubo transparente seco "trace free", com material descartável; o soro foi separado por centrifugação a 3.000 rpm, por um período de 10 a 15 minutos, e as amostras foram congeladas posteriormente ${ }^{13}$. Os níveis séricos de zinco foram determinados mediante espectrofotometria de absorção atômica de chama, empregando espectrofotômetro Analyst 300 (Perkin-Elmer Norwalk, Ct, EUA), modelo 3100, a uma longitude de onda de $213 \mathrm{~nm}$ e com ar-acetileno ${ }^{14}$. Concentrações de zinco sérico $<65 \mu \mathrm{g} / \mathrm{dL}$ foram consideradas para indicar deficiência de zinco ${ }^{15}$. As determinações foram realizadas no Laboratório Hermes Pardini.

As coletas de sangue foram realizadas antes de o almoço ser oferecido às crianças, objetivando padronizar o horário das coletas, bem como o tempo médio de jejum de cada indivíduo. A quantidade de zinco é afetada por vários fatores, como os ritmos circadianos, as refeições e o estresse $^{16}$.

A avaliação da quantidade de zinco foi realizada por meio do conjunto de três indicadores para se obter a melhor estimação do risco de deficiência de zinco numa população: zinco sérico (indicador direto), adequação da ingestão dietética de zinco alimentar (indicador dietético) e estatura/idade (indicador funcional) ${ }^{17}$. Posteriormente, a concentração de zinco no soro foi tratada como variável dependente, uma vez que é considerada o melhor bioindicador de deficiência de zinco ao refletir o consumo de zinco na dieta, responder consistentemente à suplementação com zinco e apresentar dados de referência para a maioria dos grupos etários e gêneros ${ }^{17}$. Como variáveis independentes foram consideradas:

- Características biológicas das crianças: sexo; idade (em meses); e peso ao nascer, ordenado em duas categorias: baixo peso ( $<2500 \mathrm{~g}$ ), peso normal ( $\geq 2500 \mathrm{~g}$ ). A idade das crianças foi calculada a partir da diferença entre a data de nascimento e a data da entrevista. Os dados de peso ao nascer e a data de nascimento foram obtidos do cartão de saúde da criança.

- Alimentação infantil: amamentação (criança amamentada e criança não amamentada); aleitamento materno ( $<24$ meses e $\geq 24$ meses); e aleitamento materno exclusivo ( $<6$ meses e $\geq 6$ meses).

- Antecedentes familiares: idade das mães (em anos); estatura/idade das mães, ordenado em duas categorias: baixa estatura $(<155,0 \mathrm{~cm})$, estatura normal $(\geq 155,0 \mathrm{~cm})$; e IMC das mães, ordenado em quatro categorias: baixo peso $\left(<18,5 \mathrm{~kg} / \mathrm{m}^{2}\right)$, peso normal $\left(18,5 \mathrm{~kg} / \mathrm{m}^{2}-24,9 \mathrm{~kg} / \mathrm{m}^{2}\right)$, sobrepeso $\left(25,0 \mathrm{~kg} / \mathrm{m}^{2}-29,9 \mathrm{~kg} / \mathrm{m}^{2}\right)$, obesidade $\left(\geq 30,0 \mathrm{~kg} / \mathrm{m}^{2}\right)$.

- Condições socioeconômicas: tipo de casa (própria, alugada, cedida/doada, invadida); núme-

\footnotetext{
3 Foram tomados os seguintes cuidados: limpeza total das salas de coleta antes e durante a coleta, assim como a proibição de fumar e da entrada de pessoas estranhas; assepsia, com utilização de álcool, da pele da criança na parte da veia antecubital antes de coletar o sangue; manutenção dos materiais e equipamentos cobertos e descontaminados por lavagem com $\mathrm{HCl}$ e água destilada e deionizada; assepsia com álcool das mãos e braços dos técnicos de laboratório e ajudantes, assim como a não utilização de luvas para a coleta de sangue e a proibição de lavagem das mãos com sabonete; a transferência do soro foi realizada tubo a tubo.
} 
ro de cômodos no domicílio ( $<3$ e $\geq 4)$; número de indivíduos por domicílio ( $<6$ e $\geq 6$ ); e renda familiar mensal per capita categorizada, considerando o salário-mínimo da época. Os dados foram obtidos da ficha de identificação da criança.

A digitação dos dados foi realizada com dupla entrada independente em planilhas do programa Excel (Microsoft Inc., Estados Unidos), de maneira a possibilitar a unificação entre eles através de uma única variável identificadora da criança. Após o término da digitação, os dois bancos de dados foram cruzados com a utilização do aplicativo Validate do programa Epi Info v. 6.04b (WHO/CDC, Atlanta, Estados Unidos), a fim de verificar a consistência dos dados e gerar o banco final que foi usado para análise estatística.

Para testar a normalidade da distribuição das concentrações séricas de zinco, foi utilizado o teste de Kolmogorov-Smirnov. Na comparação de médias para identificar diferenças estatísticas entre as concentrações de zinco no soro de dois grupos, utilizou-se o teste " $t$ " de Student e a análise de variância na comparação de médias entre mais de dois grupos. Em todas as etapas foi considerado o nível de significância estatística de 5\% $(p<0,05, \alpha=0,05)$. Os testes foram realizados usando o programa SPSS versão 16.0.

Todas as diretrizes éticas da Resolução $n^{\circ}$ 196/96 do Conselho Nacional de Saúde foram contempladas e o projeto maior foi aprovado pelo Comitê de Ética em Pesquisa da Universidade Estadual da Paraíba, protocolado sob o número 0021.0.133.000-09. Todos os participantes assinaram um termo de consentimento livre e esclarecido antes de sua inclusão na amostra.

Após o resultado da avaliação bioquímica e do estado nutricional, os pais foram contatados para esclarecimentos acerca do estado de saúde das crianças e correspondentes orientações nutricionais.

\section{RES U L T A D O S}

Da amostra de 256 crianças, registrou-se um total de 21 perdas, motivadas por recusa para a participação de crianças no estudo, impossibilidade de coleta de sangue e amostras hemolisadas.

Verificou-se uma prevalência de deficiência de zinco no soro de 16,2\%, com Média (M) de

Tabela 1. Avaliação do estado nutricional de zinco com a utilização do conjunto de indicadores recomendados pelo IZiNCG: Prevalência de deficit de zinco no soro, de inadequação dietética de zinco e de deficit de estatura para idade em crianças pré-escolares assistidas em creches do Estado da Paraíba segundo a variável sexo. Paraíba, 2008-2009.

\begin{tabular}{|c|c|c|c|c|c|c|}
\hline \multirow{3}{*}{$\begin{array}{l}\text { Indicador } \\
\text { Níveis de zinco no soro }\end{array}$} & \multirow{2}{*}{\multicolumn{2}{|c|}{ Total }} & \multicolumn{4}{|c|}{ Sexo } \\
\hline & & & \multicolumn{2}{|c|}{ Masculino } & \multicolumn{2}{|c|}{ Feminino } \\
\hline & $\mathrm{n}=\mathbf{2 3 5}$ & $\%$ & $\mathrm{n}=121$ & $\%$ & $n=114$ & $\%$ \\
\hline Deficit de zinco $(<65 \mu \mathrm{g} / \mathrm{dL})$ & 38 & 16,2 & 21 & 17,4 & 17 & 15,0 \\
\hline Normal $(\geq 65 \mu \mathrm{g} / \mathrm{dL})$ & 197 & 83,8 & 100 & 82,6 & 97 & 85,0 \\
\hline Média $(\mu \mathrm{g} / \mathrm{dL})$ & \multicolumn{2}{|c|}{76,29} & \multicolumn{2}{|c|}{76,53} & \multicolumn{2}{|c|}{76,03} \\
\hline Desvio-Padrão & \multicolumn{2}{|c|}{$(12,97)$} & \multicolumn{2}{|c|}{$(12,21)$} & \multicolumn{2}{|c|}{$(13,78)$} \\
\hline Adequação dietética de zinco ${ }^{a}$ & $\mathrm{n}=\mathbf{2 3 5}$ & $\%$ & $n=121$ & $\%$ & $n=114$ & $\%$ \\
\hline Inadequado & 39 & 16,6 & 21 & 17,4 & 18 & 15,8 \\
\hline Adequado & 196 & 83,4 & 100 & 82,6 & 96 & 84,2 \\
\hline Estatura para a idade $(E / /)^{\mathbf{b}}$ & $\mathrm{n}=235$ & $\%$ & $n=121$ & $\%$ & $n=114$ & $\%$ \\
\hline Deficit de estatura (E/I <-2DP) & 18 & 7,7 & 10 & 8,3 & 8 & 7,0 \\
\hline Estatura adequada (E/I $\geq-2 D P$ ) & 217 & 92,3 & 111 & 91,7 & 106 & 93,0 \\
\hline
\end{tabular}

${ }^{a} p:$ 0,550 na determinação de diferença entre as médias das concentrações de zinco no soro, segundo a adequação dietética de zinco; ${ }^{\mathbf{b}} p=0,273$ na determinação de diferença entre as médias das concentrações de zinco no soro, segundo a estatura para a idade.

DP: desvio-padrão; E/l: estatura/idade; IZiNCG: International Zinc Nutrition Consultative Group. 
$76,29 \mu \mathrm{g} / \mathrm{dL}$ e Desvio-Padrão (DP) = 12,97). O percentual de meninas e meninos que apresentaram deficit de zinco no soro foi de $15 \%$ e $17,4 \%$ respectivamente, com médias de $76,53 \mu \mathrm{g} / \mathrm{dL}$, ( $D P=12,21)$ e $M=76,03 \mu \mathrm{g} / \mathrm{dL}(\mathrm{DP}=13,78)$. Considerando as prevalências de inadequação dietética de zinco e de deficit de estatura para idade, seguindo as recomendações do International Zinc Nutrition Consultative Group, obtiveram-se valores de $16,6 \%$ e $7,7 \%$, respectivamente (Tabela 1). Cabe ressaltar que para estimar a inadequação dietética de zinco, a alimentação das crianças, baseada em alimentos refinados, foi caracterizada como de adequada biodisponibilidade de zinco.

A descrição da população investigada e os resultados das análises de associação entre as médias das concentrações de zinco no soro e as variáveis independentes do estudo estão apresentados na Tabela 2. Das 235 crianças avaliadas, $77,4 \%$ tinham entre 37 e 60 meses, e apenas $1,3 \%$ menos de um ano. Verificou-se uma proporção de $51,5 \%$ de meninos e $48,5 \%$ de meninas. A média das concentrações de zinco no soro entre as diferentes faixas etárias e entre os sexos não apresentou diferença significativa. A média das concentrações de zinco no soro foi menor, porém não estatisticamente significante, nas crianças que nasceram com baixo peso em comparação às crianças cujo peso ao nascimento foi normal $(M=75,86 D P=11,55$ versus $M=78,86 D P=14,18$; $p=0,422$ ).

As questões relacionadas à alimentação das crianças revelaram que 93,2\% delas foram amamentadas, entretanto menos da metade $(41,3 \%)$ consumiu leite materno de forma exclusiva durante 6 meses ou mais. Em relação ao tempo de amamentação, apenas 30,2\% das crianças foram amamentadas por mais de um ano. Não foi verificada associação entre as concentrações séricas reduzidas de zinco e as categorias das diferentes variáveis relacionadas com o aleitamento materno.

Em relação às condições maternas, mais da metade $(58,3 \%)$ das mães do estudo apresentou-se na faixa etária entre 20 e 30 anos.
Aproximadamente $36,0 \%$ delas tinham 30 anos ou mais, e apenas 4,3\%, menos que 20 anos. Quanto à estatura das mães, 46\% apresentaram baixa estatura para a idade, já em relação ao IMC, os valores indicaram que $43,4 \%$ delas estavam com sobrepeso/obesidade. Percebe-se que a média de zinco no soro mostrou diferença estatisticamente significante para a variável IMC da mãe. As baixas concentrações de zinco no soro se associaram com o IMC materno baixo: filhos de mães com baixo peso apresentaram níveis séricos menores desse mineral em comparação com as crianças de mães que apresentavam eutrofia.

Quanto à situação de moradia, 55,7\% das crianças residiam em casa própria, $80,0 \%$ das casas tinham quatro cômodos ou mais e 71,1\% das crianças moravam com menos de 6 pessoas. A renda per capita foi inferior a meio salário-mínimo para $86,0 \%$ das famílias estudadas. A média das concentrações de zinco no soro foi maior nas crianças que moravam em casas com 4 ou mais cômodos no domicílio, sendo a diferença não estatisticamente significante $(\mathrm{M}=84,98 \mathrm{DP}=21,96$ versus $\mathrm{M}=75,32 \mathrm{DP}=11,06 ; p=0,064)$.

\section{I S C U S S Ã O}

O principal indicador recomendado pelo IZiNCG para avaliar o estado nutricional de zinco é a concentração do mineral no soro. De acordo com Cesar et al. ${ }^{16}$, esse indicador é o mais amplamente utilizado e o único com dados populacionais de referência para estimativa de zinco. Portanto, uma proporção elevada de pessoas com baixas concentrações de zinco no soro sugere um alto risco de deficiência nessa população.

A crítica mais contundente à utilização de indicadores sanguíneos de zinco para avaliar a quantidade desse mineral está relacionada à sensibilidade para detectar estados carenciais mais leves, além do inconveniente de as concentrações sanguíneas estarem influenciadas por vários fatores, como idade, sexo, tipo de dieta, momento do dia, condições maternas e desenvolvimento de processos infecciosos ${ }^{18}$. 
Tabela 2. Distribuição das características de crianças pré-escolares assistidas em creches do Estado da Paraíba e associação com as concentrações de zinco no soro. Paraíba, 2008-2009.

\begin{tabular}{|c|c|c|c|c|c|}
\hline \multirow{2}{*}{ Variáveis } & \multicolumn{2}{|c|}{ Total } & \multicolumn{3}{|c|}{ Níveis de zinco no soro } \\
\hline & $n=235$ & $\%$ & $\mathrm{M}$ & DP & $p$ \\
\hline Características biológicas das crianças & & & & & 0,771 \\
\hline \multicolumn{6}{|l|}{ Sexo } \\
\hline Masculino & 121 & 51,5 & 76,03 & 13,78 & \\
\hline Feminino & 114 & 48,5 & 76,53 & 12,21 & \\
\hline Idade da criança (meses) & & & & & 0,363 \\
\hline $6-12$ & 3 & 1,3 & 76,12 & 11,38 & \\
\hline $13-36$ & 50 & 21,3 & 76,25 & 17,08 & \\
\hline $37-72$ & 182 & 77,4 & 86,90 & 25,21 & \\
\hline Peso ao nascer & & & & & 0,422 \\
\hline Baixo (<2500g) & 20 & 8,5 & 75,86 & 11,55 & \\
\hline Normal ( $\geq 2500 \mathrm{~g})$ & 204 & 86,8 & 78,86 & 14,18 & \\
\hline Sem informação & 11 & 4,7 & 79,60 & 28,54 & \\
\hline \multicolumn{6}{|l|}{ Alimentação infantil } \\
\hline Amamentação da criança & & & & & 0,152 \\
\hline $\operatorname{Sim}$ & 219 & 93,2 & 82,13 & 14,30 & \\
\hline Não & 13 & 5,5 & 76,05 & 12,87 & \\
\hline Sem informação & 3 & 1,3 & 68,56 & 8,41 & \\
\hline Aleitamento materno & & & & & 0,291 \\
\hline$<24$ meses & 160 & 68,1 & 77,82 & 14,71 & \\
\hline$>=24$ meses & 71 & 30,2 & 75,78 & 12,19 & \\
\hline Sem informação & 4 & 1,7 & 69,07 & 6,94 & \\
\hline Aleitamento materno exclusivo & & & & & 0,823 \\
\hline$<6$ meses & 132 & 56,2 & 76,50 & 11,35 & \\
\hline$>=6$ meses & 97 & 41,3 & 76,27 & 14,25 & \\
\hline Sem informação & 6 & 2,6 & 73,08 & 8,23 & \\
\hline Antecedentes familiares & & & & & 0,834 \\
\hline \multicolumn{6}{|l|}{ Idade da mãe (anos) } \\
\hline$>=30$ & 85 & 36,2 & 78,83 & 17,68 & \\
\hline $25 \leq$ ldade $<30$ & 77 & 32,8 & 76,48 & 11,08 & \\
\hline $20 \leq 1$ dade $<25$ & 60 & 25,5 & 76,26 & 12,89 & \\
\hline$<20$ & 10 & 4,3 & 75,63 & 13,88 & \\
\hline Sem informação & 3 & 1,3 & 83,23 & 10,66 & \\
\hline Estatura/ldade da mãe & & & & & 0,621 \\
\hline Baixa $(<155,0 \mathrm{~cm})$ & 108 & 46,0 & 76,04 & 12,54 & \\
\hline Normal $(>=155,0 \mathrm{~cm})$ & 123 & 52,3 & 76,78 & 13,55 & \\
\hline Sem informação & 4 & 1,7 & 70,65 & 10,55 & \\
\hline IMC $\left(\mathrm{kg} / \mathrm{m}^{2}\right)$ da mãe ${ }^{1}$ & & & & & 0,016 \\
\hline Obesidade $(\geq 30,0)$ & 32 & 13,6 & 73,90 & 15,33 & \\
\hline Sobrepeso $(25,0$ - 29,9) & 70 & 29,8 & 75,85 & 11,40 & \\
\hline Normal $(18,5-24,9)$ & 116 & 49,4 & 80,07 (DS) & 15,00 & \\
\hline Baixo peso $(<18,5)$ & 13 & 5,5 & 71,29 (DS) & 10,93 & \\
\hline Sem informação & 4 & 1,7 & 70,65 & 10,55 & \\
\hline Condições socioeconômicas & & & & & 0,607 \\
\hline \multicolumn{6}{|l|}{ Tipo de casa } \\
\hline Própria & 131 & 55,7 & 79,14 & 10,91 & \\
\hline Alugada & 78 & 33,2 & 79,09 & 16,19 & \\
\hline Cedida/Doada & 21 & 8,9 & 76,74 & 14,63 & \\
\hline Invadida & 5 & 2,1 & 75,46 & 10,91 & \\
\hline
\end{tabular}


Tabela 2. Distribuição das características de crianças pré-escolares assistidas em creches do Estado da Paraíba e associação com as concentrações de zinco no soro. Paraíba, 2008-2009.

Conclusão

\begin{tabular}{|c|c|c|c|c|c|}
\hline \multirow{2}{*}{ Variáveis } & \multicolumn{2}{|c|}{ Total } & \multicolumn{3}{|c|}{ Níveis de zinco no soro } \\
\hline & $n=235$ & $\%$ & $\mathrm{M}$ & DP & $p$ \\
\hline \multicolumn{6}{|c|}{ Número de cômodos no domicílio } \\
\hline$<3$ & 47 & 20,0 & 75,50 & 11,80 & 0,064 \\
\hline$>=4$ & 188 & 80,0 & 79,42 & 16,64 & \\
\hline \multicolumn{6}{|c|}{$N^{\circ}$ de indivíduos por domicílio } \\
\hline$>=6$ & 68 & 28,9 & 76,42 & 13,37 & 0,803 \\
\hline$<6$ & 167 & 71,1 & 75,95 & 12,00 & \\
\hline \multicolumn{6}{|c|}{ Renda familiar mensal per capita² } \\
\hline$>=2 \mathrm{SM}$ & 0 & 0 & - & - & \\
\hline $2 \mathrm{SM}-1 \mathrm{SM}$ & 7 & 3 & 76,82 & 13,24 & 0,405 \\
\hline $1 S M-1 / 2 S M$ & 23 & 9,8 & 74,03 & 11,90 & \\
\hline$<1 / 2 \mathrm{SM}$ & 202 & 86 & 70,27 & 7,99 & \\
\hline Sem informação & 3 & 1,3 & 71,63 & 7,85 & \\
\hline
\end{tabular}

${ }^{1} \mathrm{O}$ pós-teste de Bonferroni foi utilizado para determinar a diferença entre as médias das concentrações de zinco no soro entre as diversas categorias de índice de massa corporal da mãe.

${ }^{2}$ Considerando o valor do salário-mínimo da época $(\mathrm{R} \$ 416,00)$.

SM: salário-mínimo; DS: diferença significativa (entre as médias das concentrações de zinco no soro), M: média; DP: desvio-padrão.

Considera-se risco de deficiência de zinco elevado (problema de saúde pública grave) quando a prevalência de baixo nível de zinco no soro é $>20,0 \%$, casos em que programas de intervenção devem ser implementados. Prevalências entre $10,0 \%$ e $20,0 \%$ de baixos níveis de zinco no soro devem ser interpretadas como um alto risco de deficit de zinco em alguns grupos da população, que devem ser identificados 5 . Das 235 crianças estudadas nesse trabalho, 16,2\% apresentaram níveis de zinco no soro considerados deficientes, o que sugere um alto risco de deficit de zinco na população estudada. Fávaro \& Vannucchii ${ }^{18}$ descrevem uma deficiência em níveis plasmáticos de zinco próxima à encontrada no presente estudo $(13,0 \%)(<70 \mu \mathrm{mol} / \mathrm{L})$ ao avaliar crianças pertencentes a famílias de baixa renda que residiam em três bairros da periferia de Ribeirão Preto (SP). Borges et al. ${ }^{19}$, por sua vez, apontaram prevalência de deficiência de zinco de 7,5\% (<65 $(<\mathrm{g} / \mathrm{dL})$ ao avaliarem crianças de baixa renda da região metropolitana do Rio de Janeiro, enquanto Ferraz et al. ${ }^{20}$ constataram valor bastante inferior, pois em seu estudo em pré-escolares do Programa de Saúde da Criança de Ribeirão Preto, apenas 0,5\% das crianças apresentou nível sérico de zinco $<65 \mu \mathrm{g} / \mathrm{dL}$. Estudos realizados fora do Brasil indicam prevalências superiores às apresentadas nos estudos brasileiros consultados, com cifras variando de 17,0\% na Indonésia ${ }^{21} ; 33,7 \%$ na África do Sul22; e 74,0\% na Mongólia ${ }^{23}$. As variações constatadas nas prevalências da deficiência de zinco no soro podem ser parcialmente justificadas, de maneira hipotética, dentre outros fatores, pela dificuldade de se obterem dados válidos sobre a deficiência de zinco, inclusive por meio de parâmetros bioquímicos, bem como pelo fato de a deficiência de zinco se manifestar de diferentes formas a depender da população em questão.

Diferentes estudos que tem avaliado a deficiência de zinco através dos níveis séricos têm constatado resultados diferentes. O estudo de Ferraz et al. ${ }^{20}$, por exemplo, apontou uma média de zinco no soro de $118,7 \mu \mathrm{g} / \mathrm{dL}$. Em contrapartida, Donângelo \& Azevedo ${ }^{24}$, em um estudo com 103 crianças brasileiras de baixa renda com idade entre 3 meses e 6 anos, verificaram que a média dos níveis séricos de zinco em crianças desnutridas foi de $98,3 \mu \mathrm{g} / \mathrm{dL}$, enquanto Borges et al. ${ }^{19}$, ao estudar crianças entre 1 e 5 anos pertencentes a 
famílias de baixa renda na área metropolitana do Rio de Janeiro, observaram médias de $137 \mu \mathrm{g} / \mathrm{dL}$. Quanto aos resultados obtidos na população de estudo, constataram-se teores séricos médios de zinco de $M=76,29 \mu \mathrm{g} / \mathrm{dL}(\mathrm{DP}=12,97)$, inferiores aos observados em todos os outros estudos anteriormente citados.

Além da utilização do zinco no soro, dois indicadores podem ser utilizados como evidências sugestivas sobre o risco de deficiência de zinco: a prevalência de desnutrição crônica em crianças menores de 5 anos e o risco de inadequação do consumo de zinco ${ }^{5}$.

Foram encontradas prevalências de 7,7\% de deficit de estatura para idade. Os valores são próximos da média nacional obtida na Pesquisa Nacional sobre Demografia e Saúde da Criança e da Mulher (PNDS) ${ }^{6}$, que indicou prevalência de deficit de estatura para idade de 7,0\% para o conjunto das crianças brasileiras menores de 5 anos. Esses achados coincidem com diversos outros estudos realizados no Brasil, como o de Matta et al..$^{25}$, no Rio de Janeiro (6,0\%); Bueno et al. ${ }^{26}$, em São Paulo (6,3\%); Fisberg et al. ${ }^{27}$, em São Paulo (7,0\%); Fernandes et al. ${ }^{28}$, em Pernambuco (8,1\%); Magalhães et al. ${ }^{29}$, em Minas Gerais (8,6\%); Corso et al..$^{30}$, em Florianópolis (8,7\%).

Considerando que a OMS ${ }^{11}$ estabelece que prevalências de desnutrição crônica entre $\geq 5$ $<25 \%$ indicam um problema moderado do ponto de vista de saúde pública, pode-se inferir que a população estudada apresenta um risco moderado, o que reforça a ideia de a deficiência de zinco ser um problema de saúde pública na população estudada. Nesse caso, programas de intervenção bem focalizados, que devem fazer parte de programas de saúde e nutrição mais abrangentes, são indispensáveis para a melhoria do estado nutricional em relação ao zinco. O deficit de estatura para idade deve ser incluído como indicador geral do impacto em tais situações. O monitoramento das mudanças nas prevalências de deficit de estatura não é apropriado para avaliar o impacto de programas de inter- venção com zinco, pois muitos outros fatores podem intervir ${ }^{5,31}$.

O consumo de alimentos, mesmo sendo um indicador indireto do estado nutricional, como afirma Fidelis \& Osório ${ }^{32}$, auxilia no diagnóstico nutricional, tornando possível perceber um risco potencial para o desencadeamento do problema, constituindo-se, assim, o primeiro indicador de risco nutricional. As carências de minerais e vitaminas aparecem em estágio subclínico, sem que haja comprometimento do estado nutricional, detectado pela avaliação antropométrica. Entretanto, apesar da relevância do consumo alimentar, existem poucos estudos populacionais que identificam situações alimentares em relação ao consumo de vitaminas e minerais.

Com a análise do consumo alimentar de zinco, foi revelada uma prevalência moderada de inadequação dietética $(16,6 \%)$, uma vez que o IZiNCG ${ }^{5}$ estabelece que o risco de deficiência de zinco é considerado elevado e um problema de saúde pública quando a prevalência de consumo inadequada é $>25 \%$. Nesses casos, programas de intervenção que focalizem a população em risco devem ser implementados a fim de melhorar o consumo de zinco. Cabe ressaltar que a ingestão dietética desse elemento deve ser o indicador usado pelos pesquisadores para estimar o impacto de um programa de intervenção baseado nos alimentos, e que compare a percentagem da população com inadequação dietética de zinco antes e depois da intervenção 5 .

Outros estudos também relataram altas prevalências de risco de inadequação dietética de zinco em crianças. Pode-se destacar os seguintes: Fidelis \& Osório ${ }^{32}$, no Estado de Pernambuco, observaram inadequação de 57,3\%, 43,7\% e $52,6 \%$, nas faixas etárias de 7-11 meses, $1-3$ anos e 1-4 anos respectivamente, enquanto Cavalcante et al. ${ }^{33}$, em Minas Gerais, encontraram prevalência de $99,4 \%$ ao avaliar crianças entre 12-35 meses de idade. Alguns fatores poderiam explicar esses resultados: consumo diminuído de alimentos como leite, carne vermelha, fígado e ovos, considerados as melhores fontes de zinco, e problemas 
na utilização pelo organismo, pois a ocorrência da deficiência desse mineral está associada à presença de outros constituintes dietéticos (fitatos) que inibem sua absorção ${ }^{32}$. Esse último fator deve ser o de menor importância na população estudada, uma vez que a dieta foi classificada como de adequada biodisponibilidade de zinco.

A avaliação do estado nutricional de zinco com a utilização de dados de consumo de alimentos constituiu um aspecto metodológico de grande importância, pois não existe um questionário de frequência validado para esses fins, como recomendado pelo IZiNCG, para estimar a adequação dietética de zinco. Seguimos, portanto, as recomendações atuais de avaliação com métodos retrospectivos ${ }^{5}$. Porém, além do viés de memória implícito nesses métodos ${ }^{32}$, várias dificuldades foram encontradas no processo de análise. Ressaltamos o fato de o programa de processamento de dados de consumo de alimentos Virtual Nutri não conter informação sobre o conteúdo de zinco de diversos alimentos, criando a necessidade da consulta de diferentes tabelas sobre composição de alimentos para completar as informações faltantes. Nesse processo foi constatado que essas tabelas diferem grandemente no que diz respeito à composição centesimal dos alimentos, dificultando as decisões. Não obstante, cabe ressaltar que, no intuito de conservar a qualidade dos dados, o trabalho foi padronizado, conduzido e supervisionado por uma nutricionista preparada na avaliação de consumo de alimentos. Outra dificuldade que deve ser pontuada em pesquisas sobre o tema se refere à necessidade de levar em consideração a biodisponibilidade de zinco na dieta.

Subgrupos populacionais com alto risco de deficiência de zinco devem ser identificados sob a base de características como a idade, estado fisiológico e presença de algumas condições patológicas. Nesse contexto, as crianças representam um subgrupo de grande importância com características biológicas importantes como possíveis fatores de risco na deficiência de zinco ${ }^{5}$. As médias de zinco no soro nas crianças de estudo não apre- sentaram diferenças estatísticas significantes segundo a idade. Já no estudo de Ferraz et al. ${ }^{20}$, as crianças com idades entre $\geq 48$ e $<72$ meses apresentaram valores menores do que as crianças de outras faixas etárias. Segundo os autores, é possível que, devido a altas taxas de crescimento, as necessidades de zinco sejam maiores em meninos e bebês/crianças pequenas, principalmente naquelas com baixo peso ao nascer, o que classifica esses grupos como sendo de alto risco para deficiência de zinco.

Neste estudo, apesar de a média de zinco no soro não se apresentar estatisticamente associada nem com o peso ao nascer, nem com a idade das crianças, concentrações menores foram encontradas nas crianças de menor idade e nas que nasceram com baixo peso.

Silva et al. ${ }^{34}$, ao discutirem as necessidades nutricionais do grupo materno-infantil, afirmam que o leite materno constitui a mais importante fonte de nutrientes, como o zinco, para o recém-nascido e lactente. Gibson \& Anderson ${ }^{35}$ acrescentam ainda o efeito protetor da amamentação contra as infecções gastrointestinais que podem causar perdas excessivas de zinco. Não obstante, o fato de a criança ter sido amamentada ou não, assim como o tempo total de amamentação e o tempo de amamentação de forma exclusiva, resultaram em médias de zinco no soro sem associação estatística.

A idade materna inferior a 20 anos, segundo Post et al. ${ }^{36}$, é considerada fator de risco para a saúde infantil. Nascimento ${ }^{37}$ afirma, ainda, que a idade materna, geralmente, encontra-se diretamente relacionada às condições sociais e ao acesso a informações sobre a melhor idade para engravidar. No presente estudo, 4,3\% das mães tinham idade inferior a 20 anos, não estando a variável associada estatisticamente ao indicador bioquímico.

Em relação às condições nutricionais maternas, a variável IMC da mãe mostrou-se estatisticamente associada às concentrações de zinco no soro, enquanto a estatura da mãe não apresentou tal associação. O estado nutricional materno pré- 
-natal e pós-natal é um fator importante no estado nutricional infantil. O estado nutricional pré-natal afeta o peso ao nascer, a morbidade e a mortalidade neonatal, e o estado nutricional de micronutrientes do recém-nascido. O estado nutricional pós-natal pode afetar a qualidade do leite materno e, portanto, a ingestão dietética de nutrientes do lactente. A pouca atenção que o estudo da relação entre o estado nutricional da mãe e o estado nutricional de seu filho tem recebido, a carência de informação sobre a magnitude da deficiência de zinco, a importância de elucidar a relação entre as deficiências de micronutrientes com o crescimento infantil, e a dificuldade na medição do estado nutricional de zinco imprimem importância ao esclarecimento da relação entre o estado nutricional das mães e seus filhos ${ }^{21}$.

Nenhuma das variáveis socioeconômicas se mostrou com diferença estatística significante em relação às médias das concentrações de zinco no soro. Não obstante, cabe ressaltar que a falta de poder aquisitivo e de satisfação das necessidades materiais de vida, que restringe as condições de higiene do ambiente familiar e o acesso a bens e serviços, atua como fator adverso ao adequado estado de saúde e nutrição na infância ${ }^{38,39}$.

No Brasil, poucos estudos sobre o estado nutricional de zinco têm sido publicados; os estudos existentes apontam um alto risco de deficit de zinco em alguns grupos da população, principalmente em crianças. Para a Região Nordeste, não há informações disponíveis sobre a prevalência e a distribuição dessa deficiência nos potenciais grupos de risco. Esse fato deve ser analisado como um dado preocupante, assim como ocorre com outras deficiências de micronutrientes, exigindo a necessidade de um melhor entendimento do problema. Os resultados do presente estudo sobre a associação das concentrações séricas de zinco com outras variáveis podem ser expressão do pouco conhecimento sobre a deficiência de zinco, cabendo, portanto, a necessidade de pesquisas sobre o tema. Estudos sobre a magnitude, distribuição e fatores de risco da deficiência de zinco em pré-escolares são indispensáveis na compreensão do problema e como base de referência para o planejamento e para a avaliação de intervenções. A necessidade de desenvolver e padronizar os métodos para a medição do estado nutricional de zinco é crucial para o desdobramento dessas pesquisas. Por ser a inadequação dietética de zinco absorvível como a causa primária da deficiência de zinco na maior parte das situações, a construção e a validação de um questionário de frequência de consumo de alimentos para estimar a adequação dietética de zinco devem ser reforçadas. Adicionalmente, um indicador bioquímico da deficiência de zinco que precise de quantidades mínimas de sangue também se torna importante.

\section{O N CLUSÃO}

A população estudada, caracterizada pelo baixo nível socioeconômico e institucionalização, apresenta risco moderado de deficiência de zinco, pois foram indicadas prevalências significativas de deficiência sérica de zinco, de consumo inadequado de zinco alimentar e de desnutrição crônica, com valores de 16,2\% (problema de saúde pública moderado), 16,6\% (inadequação dietética moderada) e 7,7\% (problema de saúde pública moderado) respectivamente. Sugere-se a necessidade de pesquisas adicionais para o aprofundamento de discussões acerca da deficiência de zinco como problema de saúde pública.

\section{A GRADECIMENTOS}

A Universidade Estadual da Paraíba pelo finaciamento concedido (processo 056/2008). Aos dirigentes do governo da Paraíba, assim como aos funcionários, estudantes, pais e crianças, que, de uma forma ou de outra, viabilizaram o desenvolvimento da pesquisa.

\section{COLABORADORES}

D. FIGUEROA PEDRAZA participou da elaboração do projeto, da concepção do artigo, da revisão 
bibliográfica, da análise e da interpretação dos dados, da redação e da revisão final do artigo. A.C.D. ROCHA participou da concepção do artigo, da revisão bibliográfica, da análise e interpretação dos dados e da redação final do artigo. E.O. QUEIROZ e C.P.C. SOUSA participaram da análise e da interpretação dos dados e da redação final do artigo.

\section{REFERÊ N CIAS}

1. Rivera JA, Hotz C, González-Cossío T, Neufeld L, García-Guerra A. The effect of micronutrient deficiencies on child growth: a review of results from community-based supplementation trials. J Nutr. 2003; 133(11):4010S-20S.

2. Brasil. Ministério da Saúde do Brasil. Saúde da criança: acompanhamento do crescimento e desenvolvimento infantil. Brasília: MS; 2002.

3. Rivera-Dommarco J, Shamah-Levy T, VillalpandoHernández S, González-Cossío T, Hernández-Prado B, Encuesta Nacional de Nutrición 1999. Estado nutricio en niños y mujeres en México. Cuernavaca, Morelos, México: Instituto Nacional de Salud Pública; 2001.

4. Duarte ACG. Avaliação nutricional: aspectos clínicos e laboratoriais. São Paulo: Atheneu; 2007.

5. International Zinc Nutrition Consultative Group. Assessment of the risk of zinc deficiency in populations and options for its control. Hotz $\mathrm{C}$ and Brown KH, editores. Food Nutr Bull. 2004; 25(1 Suppl 2):S130-62.

6. Brasil. Ministério da Saúde. Pesquisa nacional sobre demografia e saúde da criança e da mulher. Brasília: MS; 2006.

7. Habitch JP. Standardization of quantitative epidemiological methods in the field. Bol Ofi Sanit Panam. 1974; 74:375-84.

8. Serra Majem LI, Aranceta Bartrina J, Mataix Verdú J. Nutrición y salud pública: métodos, bases científicas y aplicaciones. Barcelona: Masson; 1995.

9. World Health Organization. Physical status: the use and interpretation of anthropometry: report of an Expert Committee. Geneva: WHO; 1995. Technical Report Series.

10. Onis M, Garza C, Victora CG, Onyango AW, Frongillo EA, Martines J. For the WHO Multicentre Growth Reference Study Group. The WHO Multicentre Growth Reference Study: planning, study designed methodology. Food Nutr Bull. 2004; 25 (Suppl 1):15-26.

11. World Health Organization. WHO global database on child growth and malnutrition. Geneva: WHO;
2007 [cited 2007 Mar 25]. Available from: <http:// www.who.int/nutgrowthdb/index.html>.

12. National Center for Health Statistics, Centers for Disease Control and Prevention. Washington (DC): CDC; 2000 [cited 2007 Apr 1]. Available from: <http://www.cdc.gov/growthcharts>.

13. Henry JB. Clinical diagnosis and management by laboratory methods. Philadelphia (PA): W.B. Saunders; 1991.

14. Sandstrom B. Diagnosis of zinc deficiency and excess in individuals and populations. Food Nutr Bull. 2001; 22(2):133-37.

15. Hess SY, Peerson J, King J, Brown K. Use of serum zinc concentration as an indicator of population zinc status. Food Nutr Bull. 2007; 28(3 Suppl): 403S-29S.

16. Cesar TB, Wada SR, Borges RG. Zinco plasmático e estado nutricional em idosos. Rev Nutr. 2005; 18(3):357-65. doi: 10.1590/S1415-527320050 00300008.

17. Benoist B, Darnton-Hill I, Davidsson L, Fontaine O, Hotz C. Conclusions of the Joint WHO/UNICEF/ IAEA/IZiNCG Interagency Meeting on Zinc Status Indicators. Food Nutr Bull. 2007; 28(3 Suppl): S480-84.

18. Favaro RMD, Vannucchi H. Níveis plasmáticos de zinco e antropometria de crianças da periferia de centro urbano no Brasil. Rev Saúde Pública. 1990; 24(1):5-10.

19. Borges CVD, Veiga APB, Barroso GS, Jesus EFO, Serpa RFB, Moreira S. et al. Associação entre concentrações séricas de minerais, índices antropométricos e ocorrência de diarréia entre crianças de baixa renda da região metropolitana do Rio de Janeiro. Rev Nutr. 2007; 20(2):159-69. doi: 10.15 90/S1415-52732007000200005.

20. Ferraz IS, Daneluzzi JC, Vannucchi H, Jordão Jr AA, Ricco RG, Del Ciampo LA, et al. Nível sérico de zinco e sua associação com deficiência de vitamina $A$ em crianças pré-escolares. J Pediatr. 2007; 83(6):512-17.

21. Dijkhuizen MA, Wieringa FT, West CE. Muherdiyantiningsih and Muhilal. Concurrent micronutrient deficiencies in lactating mothers and their infants in Indonesia. Am J Clin Nutr. 2001; 73(4):786-91.

22. Oelofse A, Van Raaij JM, Benadé AJ, Dhansay MA, Tolboom JJ, Hautvast JG. Disadvantaged black and coloured infants in two urban communities in the Western Cape, South Africa differ in micronutrient status. Public Health Nutr. 2002; 5(2):289-94.

23. Lander RL, Enkhjargal T, Batjargal J, Bailey KB, Diouf S, Green TJ, et al. Multiple micronutrient deficiencies persist during early childhood in Mongolia. Asia Pac J Clin Nutr. 2008; 17(3):429-40. 
24. Donângelo CM, Azevedo CE. Zinco sérico em crianças brasileiras de famílias de baixa renda. Arch Latinoam Nutr. 1984; 34(2):290-7.

25. Matta IEA, Veiga GV, Baião MR, Santos MMAS, Luiz RR. Anemia em crianças menores de cinco anos que freqüentam creches públicas do município do Rio de Janeiro, Brasil. Rev Bras Saude Mater Infant. 2005; 5(3):349-57.

26. Bueno MB, Selem SSC, Arêas JAG, Fisberg RM. Prevalência e fatores associados à anemia entre crianças atendidas em creches públicas de São Paulo. Rev Bras Epidemiol. 2006; 9(4):462-70.

27. Fisberg RM, Marchioni DML, Cardoso MRA. Estado nutricional e fatores associados ao déficit de crescimento de crianças freqüentadoras de creches públicas do Município de São Paulo, Brasil. Cad Saúde Pública. 2004; 20(3):812-7.

28. Fernandes TFS, Diniz AS, Cabral PC, Oliveira RS, Lóla MMF, Silva SMM, et al. Hipovitaminose A em pré-escolares de creches públicas do Recife: indicadores bioquímico e dietético. Rev Nutr. 2005; 18(4): 471-80. doi: 10.1590/S1415-527320050004000 03.

29. Magalhães P, Ramalho RA, Colli C. Deficiência de ferro e de vitamina A: avaliação nutricional de pré-escolares de Viçosa (MG/Brasil). Nutrire. 2001; 21: 41-56.

30. Corso ACT, Viteritte P, Peres MA. Prevalência de sobrepeso e sua associação com a área de residência em crianças menores de 6 anos de idade matriculadas em creches públicas de Florianópolis, Santa Catarina, Brasil. Rev Bras Epidemiol. 2004; 7(2):201-9.

31. Christa L, Walker F, Black RE. Functional indicators for assessing zinc deficiency. Food Nutr Bull. 2007; 28(Suppl 3):454S-79S.

32. Fidelis CMF, Osório MM. Consumo alimentar de macro e micronutrientes de crianças menores de cinco anos no Estado de Pernambuco, Brasil. Rev Bras Saúde Matern Infant. 2007; 7(1):63-74.

33. Cavalcante AAM, Tinôco ALA, Cotta RMM, Ribeiro $\mathrm{RCL}$, Pereira CAS, Franceschini SCC. Consumo alimentar e estado nutricional de crianças atendidas em serviços públicos de saúde do município de Viçosa, Minas Gerais. Rev Nutr. 2006; 19(3):321-30. doi: 10.1590/S1415-52732006000300003.

34. Silva LSV, Thiapó AP, Souza GG, Saunders C, Ramalho A. Micronutrientes na gestação e lactação. Rev Bras Saúde Matern Infant. 2007; 7(3):237-44.

35. Gibson RS, Anderson VP. A review of interventions based on dietary diversification or modification strategies with the potential to enhance intakes of total and absorbable zinc. Food Nutr Bull. 2007; 30(1 Suppl):S108-43.

36. Post CLA, Victora CG, Barros AJD. Entendendo a baixa prevalência de déficit de peso para estatura em crianças brasileiras de baixo nível sócio-econômico: correlação entre índices antropométricos. Cad Saúde Pública. 2000; 16(1):73-82.

37. Nascimento LFC. Estudo transversal sobre fatores associados ao baixo peso ao nascer a partir de informações obtidas em sala de vacinação. Rev Bras Saude Mater Infant. 2003; 3(1):37-42.

38. Oliveira VA, Assis AMO, Pinheiro SMC, Barreto ML. Determinantes dos déficits ponderal e de crescimento linear de crianças menores de dois anos. Rev Saúde Pública. 2006; 40(5):874-82.

39. Fundo das Nações Unidas para a Infância. Saúde e nutrição da criança nordestina: pesquisas estaduais, 1987-1992. Brasília: Unicef; 1995.

Recebido em: 27/5/2010

Versão final reapresentada em: 26/1/2011 Aprovado em: 22/2/2011 